\title{
The Renal Excretion of Bilirubin in Dogs with Obstructive Jaundice *
}

\author{
Milford Fulop and Paul Brazeau \\ (From the Departments of Medicine and Pharmacology, Albert Einstein College of Medicine \\ and the Bronx Municipal Hospital Center, New York, N. Y.)
}

Dogs and humans excrete only conjugated bilirubin in the urine, principally the diglucuronide, and unconjugated bilirubin is not excreted by the kidneys (1). Previous studies concerning the renal excretion of bilirubin have not resolved the issue of whether it is filtered through the glomeruli or is secreted by the tubules $(2,3)$.

Bilirubin in the plasma has been reported to be completely bound to proteins $(4,5)$ regardless of its state of conjugation. Possibly, however, a small portion could be filterable through the glomeruli, although it might be difficult to measure such a portion precisely. ${ }^{1}$ Under such circumstances, conventional renal clearance methods which compare bilirubin clearance $\left(C_{B}\right)$ with glomerular filtration rate (GFR) will not define the excretory mechanism.

In the present studies the renal excretion of bilirubin in $\operatorname{logs}$ with obstructive jaundice was therefore examined with other techniques as well. The methods employed were $a$ ) the administration of inhibitors of tubular secretory function, $b$ ) stop-flow experiments, and $c$ ) partial ureteral obstruction. The results were most consistent with excretion of the major portion of bilirubin by glomerular filtration. It is possible that there is also a small contribution from tubular secretion.

\section{Methods}

Subjects. The experiments were performed in 40 mongrel female dogs whose weights ranged from 9 to $20 \mathrm{~kg}$. Jaundice was produced by ligation of the com-

* Submitted for publication July 30, 1963; accepted February 13, 1964.

A preliminary report of this work was published as an abstract. Clin. Res. 1963, 11, 240.

Supported hy grants from the U. S. Public Health Service (A-5503) and the American Cancer Society.

1 Such a fraction could be either unbound bilirubin glucuronide or bilirubin glucuronide bound to a filterable carrier molecule. mon bile duct under sterile conditions during intravenous pentobarbital anesthesia. Six to 14 days after operation, when the total plasma bilirubin levels were between 2.4 and $8.0 \mathrm{mg}$ per $100 \mathrm{ml}$, renal function studies were performed. $\mathrm{C}_{\mathrm{B}}$ ranged between 1 and $2.5 \%$ of the GFR when total plasma bilirubin was used as the denominator in the clearance formula. Plasma bilirubin was fractioned into "15-minute direct-reacting" and total diazotizable pigment in 24 specimens obtained from six dogs between 3 and 19 days after bile duct ligation. In this group the 15-minute direct-reacting fraction averaged $92 \%$ (range, 87 to $99 \%$ ) of the total plasma bilirubin, with no systematic trend during that period. ${ }^{2}$. In the present studies, the plasma bilirubin level was stable during the experimental periods on any given day. The only exceptions to this were three of the experiments in which sodium salicylate was administered.

Renal function studies. All experiments were performed under light pentobarbital anesthesia. Bladder urine collections were obtained by indwelling catheter with continuous drainage, and clearance periods were terminated with a distilled water washout. Some of the dogs underwent studies which involved cannulation of first one ureter, and then the other, on separate days. When an animal was to be used for a second study, the first ureteral cannulation via a flank incision was performed under sterile conditions. At the conclusion of such experiments the plastic catheter was removed, and the ureter ligated. Such animals tolerated the interval between the first and second study well.

Heparinized blood specimens were obtained from an indwelling jugular needle at the mid-point of each clearance period. All drugs were administered intravenously. GFR was estimated by the clearance of either creatinine or inulin at plasma (P) levels of 25 to $30 \mathrm{mg}$ per $100 \mathrm{ml}$. In addition to conventional clearance experiments two other types of study were undertaken.

a) Stop-flow experiments. These were performed according to the method of Malvin, Wilde, and Sullivan (7), using an iv infusion of 10 to $20 \%$ mannitol in $0.6 \%$

\footnotetext{
2 Seven of these specimens were also fractionated into conjugated and unconjugated bilirubin by the method of Weber and Schalm (6). The 15-minute direct-reacting fraction determined by the Malloy-Evelyn method and the conjugated bilirubin determined by this newer method were almost identical in each case.
} 
$\mathrm{NaCl}$ solution. Glucose was added to the infusion in some experiments. After ureteral urine $(U)$ flow reached 7 to $9 \mathrm{ml}$ per minute, two control free-flow periods were obtained, and the ureteral catheter was then occluded for 6 to 7 minutes. After release of the occlusion serial urine specimens of 1.2 to $1.6 \mathrm{ml}$ were collected, ${ }^{3}$ and the study was terminated with the collection of two postobstruction free-flow clearance periods. In the first 11 studies creatinine was given in the sustaining infusion, and inulin was given 1 minute before termination of the occlusion to signal the arrival of "new filtrate." In the last four studies inulin was given in the sustaining infusion, and creatinine was given 1 minute before release of the occlusion. Specimens were analyzed for bilirubin, creatinine, inulin, and glucose, and in the last four experiments, for protein. The graphic presentations are given in terms of the ratio of $U / P_{b 11 \text { rubln }}$ to $\mathrm{U} / \mathrm{P}_{\text {ereatinine }}$ or $\mathrm{U} / \mathrm{P}_{\mathrm{inulin}}$ as suggested by Pitts, Gurd, Kessler, and Hierholzer (8).

b) Acute partial ureteral obstruction. Animals in which one ureter had been cannulated through a flank incision were given a sustaining infusion of $5 \%$ or $6 \%$ mannitol in $0.6 \% \mathrm{NaCl}$ solution. The urine flow usually came into volume equilibrium with the infusion in 60 to 90 minutes. When ureteral urine volume reached 2 to $3 \mathrm{ml}$ per minute, three (or occasionally two) control 10-minute clearance periods were taken, after which the ureteral catheter was elevated 20 to $50 \mathrm{~cm}$ above the kidney. After a generous discard period (consisting of at least two estimated dead space volumes), two consecutive clearance periods were taken at this level. In most of the experiments the catheter was then elevated an additional 5 to $20 \mathrm{~cm}$ and two more periods were obtained. In some of the early experiments two further urine collections were obtained after the catheter had been returned to its preobstruction level. These periods did not provide more information and were omitted in later studies. GFR was estimated by the creatinine clearance $\left(\mathrm{C}_{\mathrm{C}_{\mathbf{r}}}\right)$ in the first 13 experiments, and the inulin clearance $\left(C_{\text {In }}\right)$ was used in the last four experiments. Renal plasma flow (RPF) was estimated by the clearance of para-aminohippurate $(\mathrm{PAH})$ at plasma levels of 1.5 to $2.0 \mathrm{mg}$ per $100 \mathrm{ml}^{4}$

Chemical methods. Spectrophotometric determinations were performed in duplicate, except for the urinary bilirubin and Folin estimations in the stop-flow experiments. In those instances, single determinations were dictated by the small sample size.

a) Bilirubin. In two of the probenecid studies, urinary bilirubin was determined with a modified Fouchet reaction (9). In subsequent experiments both plasma and

3 The relatively large specimen volumes were necessary for accurate determination of bilirubin concentration.

$4 \mathrm{PAH}$ at these levels increased the urinary excretion of bilirubin by about 10 to $12 \%$ (see below). The plasma PAH level changed very little in these experiments, so that its effect on bilirubin excretion was presumably unvarying from one period to another. urinary bilirubin were determined with the MalloyEvelyn diazotization method (10) adapted for the Coleman Junior spectrophotometer. When urinary bilirubin concentration was very low, the absorbance was measured in the Coleman Senior spectrophotometer, with a $5-\mathrm{cm}$ light path cuvette. Measurements were always performed within a few hours of collection, during which the specimens were kept in aluminum foil-covered tubes at $4^{\circ} \mathrm{C}$. The urinary determinations were stable and reproducible for at least 8 to 12 hours after collection. In five partial obstruction experiments and one probenecid study, the absorbance of the urine specimens at $435 \mathrm{~m} \mu$ (the average wave length of peak absorbance of bilirubin in the urine) was measured in addition to the diazo method of determination. These two methods were compared as percentages of the respective values for the first urine specimen of the particular experiment. In 43 specimens the difference between the two, calculated as percentages, averaged $0.14 \% \pm 2.9 \%$ ( $1 \mathrm{SD}$ ), and the coefficient of correlation was +0.97 . The close correspondence between the diazo and the $435-\mathrm{m} \mu$ absorbance values supports the significance of changes in the diazo values as reflecting changes in bilirubin concentration. Urine specimens from two dogs were studied before common duct ligation was performed. The diazo color reactions were not typical of azobilirubin, but the absorbance in each case gave a concentration value that was equivalent to the excretion of $4 \mu \mathrm{g}$ of bilirubin per minute. This was less than $5 \%$ of the total urinary diazotizable material excreted by the jaundiced dogs, and hence no correction was applied for this blank.

b) Creatinine was determined in urine and acid tungstate filtrates of plasma by an alkaline picrate method (11).

c) Inulin was determined in urine and in trichloroacetic acid filtrates of plasma by the method of Higashi and Peters (12). In the last four stop-flow experiments, it was measured in an autoanalyzer ${ }^{5}$ by an adaptation of the same colorimetric procedure.

d) $P A H$ in urine and in cadmium sulfate filtrates of plasma was determined by the method of Smith and coworkers (13).

e) Glucose in urine and in barium hydroxide-zinc sulfate filtrates of plasma was determined by the NelsonSomogyi method (14).

f) Protein was measured in the urine by the method of Lowry, Rosebrough, Farr, and Randall (15).

Dialysis experiments. Five-ml samples of plasma in dialysis casing were dialyzed against $5 \mathrm{ml} 0.01 \mathrm{M}$ phosphate-buffered saline ${ }^{6}$ in $50-\mathrm{ml}$ flasks gassed with $5 \%$ $\mathrm{CO}_{2}$ and $95 \% \quad \mathrm{~N}_{2}$, usually for about 24 hours at $4^{\circ} \mathrm{C}$. The flasks were covered with aluminum foil and placed on a shaker. The volume relationships and the brevity of

5 Technicon Instrument Corp., Chauncey, N. Y.

6 The dialysis casing had been soaked in distilled water for 24 hours and was then wiped dry before use. The buffer solution included $0.313 \mathrm{~g} \mathrm{KH}_{2} \mathrm{PO}_{4}$ and 1.093 g $\mathrm{Na}_{2} \mathrm{HPO}_{4}$ per $\mathrm{L}$ of $0.9 \% \mathrm{NaCl}, \mathrm{pH} 7.2$. 
TABLE I

Effect of saline diuresis on urinary bilirubin excretion*

\begin{tabular}{|c|c|c|c|c|c|c|}
\hline \multirow[b]{2}{*}{ Dog } & \multicolumn{3}{|c|}{ Control } & \multicolumn{3}{|c|}{ Diuresis } \\
\hline & $\mathrm{V}$ & $\mathrm{UBV}_{\mathbf{B}}$ & $\begin{array}{l}\mathrm{C}_{B} / \\
\mathrm{C}_{\mathrm{Cr}}\end{array}$ & V & $\mathrm{U}_{\mathrm{BV}}$ & $\begin{array}{l}\mathrm{C}_{B} / \\
\mathrm{C}_{\mathrm{Cr}}\end{array}$ \\
\hline & $\begin{array}{l}\text { ml/ } \\
\text { min }\end{array}$ & $\underset{\min }{\mu g /}$ & $\%$ & ${ }_{\text {min }}^{\text {ml/ }}$ & $\underset{m i n}{\mu g /}$ & $\%$ \\
\hline E-2 & 1.4 & 31 & 1.6 & 4.4 & 29 & 1.6 \\
\hline G-3 & 2.4 & 27 & 1.5 & 4.2 & 26 & 1.4 \\
\hline
\end{tabular}

* The data given represent the averages of at least two 20-minute bladder collections of urine in each experiment. $V=$ urine volume $=$ creatinine clearance.

dialysis both mitigated against attainment of equilibrium. These conditions were nevertheless chosen in order to minimize loss of dialyzed pigment and to heighten the concentration of pigment in the dialyzate. Plasma specimens were dialyzed in the presence of certain organic anions that had been added to the buffered saline. Other specimens obtained during the clearance experiments, before and after the administration of probenecid or salicylate, were also studied. The absorption spectra of the native dialyzates were measured in a Zeiss spectrophotometer, ${ }^{7}$ and of the diazotized specimens in a Coleman Senior spectrophotometer, with cuvettes of $5-\mathrm{cm}$ light path.

\section{Results}

Diuresis and urinary alkalinization. The effect of diuresis upon urinary bilirubin excretion was assessed specifically in two experiments and observed in many others. The data in Table $I$ indicate the absence of any effect of saline diuresis in those two studies. In other experiments urine volume ranged from control levels of $1 \mathrm{ml}$ per minute up to $8 \mathrm{ml}$ per minute, also without influencing bilirubin excretion.

The effect of urinary alkalinization was examined in three studies in which sodium bicarbonate was infused at rates between 1,200 and $2,700 \mu$ moles per minute, and in three others in which acetazolamide was administered in doses of between 5 and $25 \mathrm{mg}$ per $\mathrm{kg}$. The data in Table II are representative of the negative results in those studies.

Dialysis experiments. Ultrafiltrations of plasma were performed according to the method of Toribara, Terepka, and Dewey (16), but are not

7 Each blank used was a dialyzate of nonicteric dog plasma prepared in the same way as the dialyzate of the corresponding icteric plasma specimen. reported here because the absorption spectra of the faint yellow ultrafiltrates did not conform perfectly with those of bilirubin. Dialyzates of plasma, on the other hand, did exhibit the appropriate spectral characteristics. These were a) an absorption maximum of the native dialyzate at between 435 and $445 \mathrm{~m} \mu$ and $b$ ) maximal absorption of the violet azo derivative at 540 to $550 \mathrm{~m} \mu$. These features were the same as those of the urinary pigment of the jaundiced dogs and of chemical bilirubin in aqueous alkaline solution. ${ }^{8}$

Fasting plasma specimens were dialyzed against phosphate-buffered saline as the control and against buffered saline to which had been added the sodium salt of one of the organic anions in approximately twice the concentration we wished to achieve in the plasma. The equilibrium concentrations of these agents in plasma would presumably be somewhat greater than half the original concentration, depending upon the extent of their binding to plasma proteins. The drug concentrations were high in order to enhance pigment dialyzability to permit determination of the absorption maximum of the azo derivative. The effects of $\mathrm{PAH}$, probenecid, and salicylate on plasma bilirubin dialyzability were each examined in at least three separate experiments using icteric plasma from different dogs. Each of these or-

TABLE II

Effect of urinary alkalinization on urinary bilirubin excretion*

\begin{tabular}{|c|c|c|c|c|c|c|}
\hline \multirow[b]{2}{*}{ Dog } & \multicolumn{3}{|c|}{ Control } & \multicolumn{3}{|c|}{ Alkalinization } \\
\hline & Urine & $\mathrm{U}_{\mathrm{BV}}$ & $\begin{array}{l}\mathrm{C}_{\mathrm{B} /} / \\
\mathrm{C}_{\mathrm{Cr}}\end{array}$ & Urine & $\mathrm{U}_{B} \mathrm{~V}$ & $\begin{array}{l}\mathrm{C}_{\mathrm{B}} / \\
\mathrm{C}_{\mathrm{Cr}_{\mathrm{r}}}\end{array}$ \\
\hline & $p H$ & $\underset{\min }{\mu g /}$ & $\%$ & $p H$ & $\underset{m i n}{\mu g /}$ & $\%$ \\
\hline F-1 & $(5-6) \dagger$ & 31 & 1.5 & $(7-8) \dagger$ & 30 & 1.6 \\
\hline G-1 & 5.3 & 40 & 2.4 & 7.8 & 40 & 2.4 \\
\hline
\end{tabular}

* The data given represent the averages of at least two 20 -minute collections of urine, with urine removed from the bladder at the end of each period without a water wash. Dog F-1, $9 \mathrm{~kg}$, received $90 \mathrm{mg}$ acetazolamide intravenously as a prime, followed by $1.5 \mathrm{mg}$ per minute for 30 minutes before and during the postdrug periods. Dog G-1, $14 \mathrm{~kg}$,
received $12 \mathrm{~g}$ of ammonium chloride orally during the 18 hours before received $12 \mathrm{~g}$ of ammonium chloride orally during the 18 hours before the experiment. Sodium bicarbonate solution was given intravenously postcontrol periods. Abbreviations as in Table I.

$\dagger$ Urinary pH was approximated with test paper.
t

8 The dialyzates derived from both plasma specimens obtained during the probenecid clearance experiment (Table IV) yielded an inflection instead of a peak at $435 \mathrm{~m} \mu$. The azo pigment nevertheless did have an absorption maximum at $550 \mathrm{~m} \mu$. The period of dialysis was 43 hours. 
TABLE III

Effect of protein-bound organic anions on plasma bilirubin dialyzability*

\begin{tabular}{|c|c|c|c|c|}
\hline \multirow[b]{2}{*}{ Agent } & \multirow{2}{*}{$\begin{array}{c}\text { Con- } \\
\text { centra- } \\
\text { tiont }\end{array}$} & \multirow{2}{*}{$\begin{array}{l}\text { Dura- } \\
\text { tion of } \\
\text { dialysis }\end{array}$} & \multicolumn{2}{|c|}{$\begin{array}{c}\text { Dialyzate OD, } \\
5 \mathrm{~cm}\end{array}$} \\
\hline & & & $435 \mathrm{~m} \mu$ & $\begin{array}{l}\text { Diazo, } \\
540 \mathrm{~m} \boldsymbol{\mu}\end{array}$ \\
\hline & $\begin{array}{c}m g / \\
100 \\
m l\end{array}$ & hours & & \\
\hline \multirow[t]{3}{*}{ Para-aminohippurate } & 0 & & 0.119 & 0.018 \\
\hline & 100 & 24 & 0.136 & \\
\hline & 200 & & 0.151 & 0.020 \\
\hline \multirow[t]{3}{*}{ Probenecid } & $\mathbf{0}$ & & 0.102 & 0.017 \\
\hline & 60 & 23 & 0.142 & \\
\hline & 120 & & 0.176 & 0.023 \\
\hline \multirow[t]{3}{*}{ Salicylate } & $\mathbf{0}$ & & 0.103 & 0.018 \\
\hline & 80 & 21 & 0.224 & 0.028 \\
\hline & 160 & & 0.292 & 0.038 \\
\hline
\end{tabular}

* In each case, $5 \mathrm{ml}$ plasma with a bilirubin concentration of $4.4 \mathrm{mg}$ per $100 \mathrm{ml}$ was dialyzed against $5 \mathrm{ml} 0.01 \mathrm{M}$ phosphate-buffered saline.
t Drug concentrations are given in terms of the concentration added t Drug concentrations are given in terms of the concentration added
to the buffered saline dialysis fluid. The final concentration of each agent in the plasma at equilibrium would be somewhat greater than half the indicated value.

ganic anions regularly evoked increased dialyzability of bilirubin from dog plasma. The data given in Table III derive from a representative series of studies using plasma obtained from one $\operatorname{dog} 5$ days after bile duct ligation, at which time its plasma bilirubin level was $4.4 \mathrm{mg}$ per $100 \mathrm{ml}$. The salicylate experiment was performed with fresh plasma, and the others with samples of the same plasma that had been stored at $-20^{\circ} \mathrm{C}$ until the day of use. ${ }^{9}$ Plasma specimens obtained before and after the administration of probenecid (60 $\mathrm{mg}$ per $\mathrm{kg}$ ) and salicylate (120 $\mathrm{mg}$ per $\mathrm{kg}$ ) intravenously to two dogs were also subjected to dialysis against buffered saline. The data given in Tables IV and V show increased pigment dialyzability after the administration of those agents.

Inhibitor experiments. Probenecid administered in a dose of $25 \mathrm{mg}$ per $\mathrm{kg}$, in three experiments, and $60 \mathrm{mg}$ per $\mathrm{kg}$ in one experiment, did not cause a decrease in $C_{B}$ or $C_{B} / G F R$. In the first two studies in which urinary bilirubin was determined by the Fouchet reaction, there was no

9 The dialyzable fraction was stable during such storage for at least 3 months. The variation in the absorbancies of the control dialyzates in Table III was attributable to using different lengths of dialysis casing in different runs, thereby altering the extent of dialysis from one run to another. In any one run all of the dialysis sacs were prepared with scrupulous uniformity. significant change in $\mathrm{C}_{\mathrm{B}} / \mathrm{C}_{\mathrm{Cr}}$ after the administration of the drug. In the other two studies in which urinary bilirubin was determined by diazotization, $\mathrm{C}_{\mathrm{B}} / \mathrm{GFR}$ increased about $20 \%$. One of those dogs was given a dose of $25 \mathrm{mg}$ per $\mathrm{kg}$, and the other was given $60 \mathrm{mg}$ per $\mathrm{kg}$. Table IV summarizes the last study. An explanation for the differing responses is not evident, but in no case did this inhibitor cause a decrease in bilirubin excretion. Plasma obtained just before and just after the administration of probenecid in the last experiment was subjected to dialysis. In keeping with the results found in vitro, the data in Table IV show an increase in dialyzable pigment in the postprobenecid plasma. ${ }^{8}$

Competitor experiments. The effect of $\mathrm{PAH}$ administration was assessed in four studies. In three the plasma level of PAH was varied between 1.0 and $2.5 \mathrm{mg}$ per $100 \mathrm{ml}$. At these levels there was a 10 to $12 \%$ increase in $C_{B}$ and $C_{B} / C_{\text {In }}$ compared with control periods. In the fourth study a dose of $50 \mathrm{mg}$ per $\mathrm{kg}$ was given very rapidly. There was a $22 \%$ decrease in $\mathrm{C}_{\mathrm{Cr}}$ which was unattended by any change in urinary bilirubin excretion $\left(\mathrm{U}_{B} V\right)$ or $C_{B}$, so that $C_{B} / C_{C r}$ rose $25 \%$.

Sodium salicylate was given intravenously in four experiments in single doses ranging from 135 to $230 \mathrm{mg}$ per $\mathrm{kg}$. $\mathrm{U}_{\mathrm{B}} \mathrm{V}$ increased in each study (24 to $74 \%$ over control values). $\mathrm{U}_{\mathrm{B}} \mathrm{V} /$ GFR increased between 22 and $50 \%$ over control values, the largest increase following the largest dose. Calculations of $C_{B}$ have uncertain significance when plasma bilirubin levels are changing, and the plasma bilirubin levels did decrease in all of the salicylate experiments. The results of one clearance experiment are given in Table $\mathrm{V}$ together with the findings on dialysis of plasma specimens. In accord with the previously cited in vitro study, bilirubin dialyzable from plasma increased after the administration of salicylate.

Partial ureteral obstruction. In these experiments disproportionate changes in GFR and $\mathrm{RPF}$ were produced in order to learn whether $\mathrm{C}_{\mathrm{B}}$ paralleled one or the other of these parameters. Seventeen experiments were performed in 13 jaundiced dogs, and a total of 56 clearance periods was obtained at various levels of increased ure- 
TABLE IV

Effect of probenecid on urinary bilirubin excretion and on plasma bilirubin dialyzability*

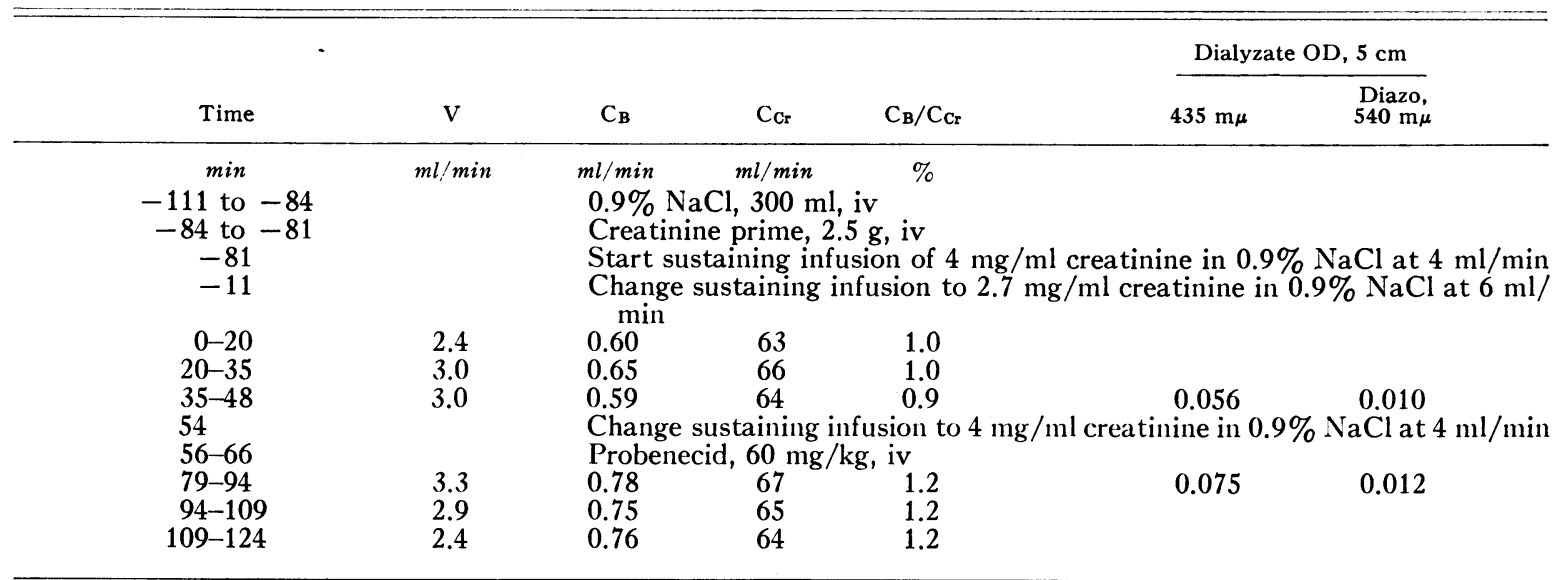

* Dog 12-63, $12 \mathrm{~kg}$, underwent common bile duct ligation 14 days before the experiment. Urine was collected from the bladder. Plasma bilirubin, $2.4 \mathrm{mg}$ per $100 \mathrm{ml}$. $5 \mathrm{ml}$ of each plasma specimen was dialyzed against $5 \mathrm{ml}$ of phosphatebuffered saline for 43 hours. Abbreviations as in Table I.

teral pressure. A typical protocol is given in Table VI. GFR was estimated by the exogenous $\mathrm{C}_{\mathrm{Cr}}$ in 13 experiments and by $\mathrm{C}_{\mathrm{In}}$ in four. The two periods at each pressure level yielded similar results, so these clearance values were averaged. These were compared with the averages of the control clearances obtained from the same kidney before ureteral pressure had been increased, and the percentages of changes from the control periods were calculated. In about one-quarter of the experiments GFR and RPF decreased proportionately. In 19 of 26 paired clearance periods the percentage of decrease in GFR exceeded the decrease in RPF. Indeed, in eight of these 26 paired periods, while GFR decreased, RPF either did not change, or actually increased. The increase in RPF in the latter experiments may have been related to increasing plasma volume as urine flow lagged behind the infusion rate after the imposition of increased ureteral pressure. In two paired periods in one dog, the percentage of decrease in RPF exceeded that in GFR, but the $C_{B}$ nevertheless remained proportionate to GFR. This animal was found at autopsy to have chronic pyelonephritis.

The percentage of decrease in $C_{B}$ was very

TABLE V

Effect of sodium salicylate on urinary bilirubin excretion and on plasma bilirubin dialyzability*

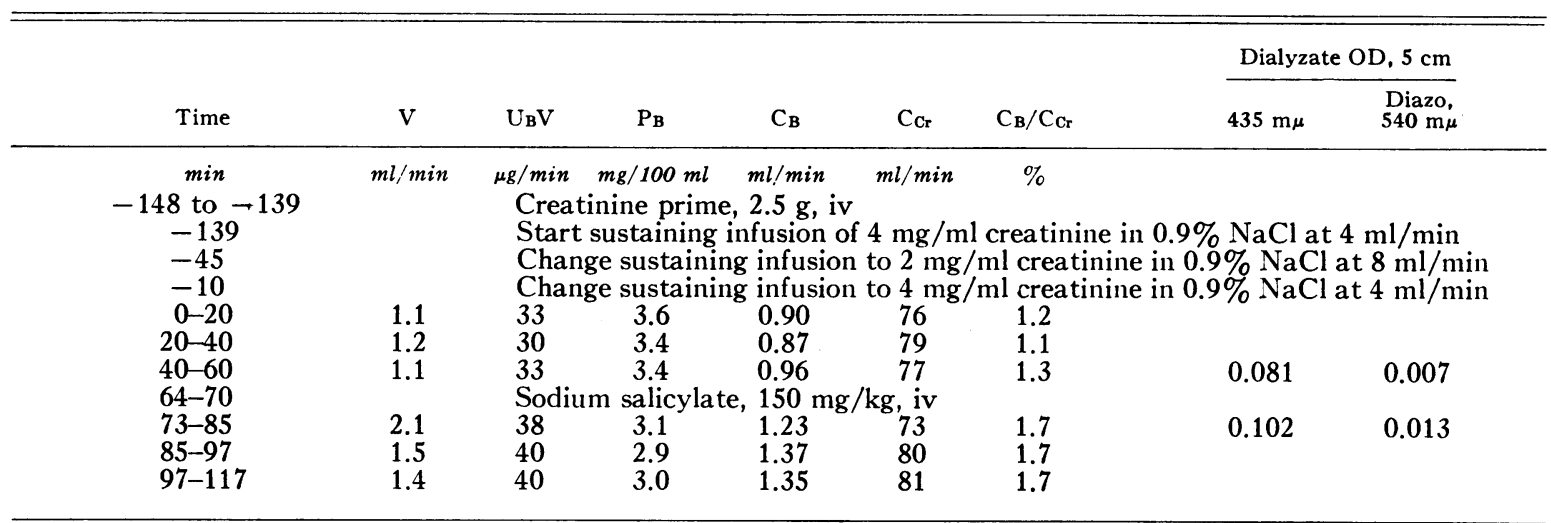

* Dog 11-63, $13 \mathrm{~kg}$, underwent common bile duct ligation 21 days before the experiment. Urine was collected from the bladder. $5 \mathrm{ml}$ of each plasma specimen was dialyzed against $5 \mathrm{ml}$ of phosphate-buffered saline for 25 hours. $P_{B}$ $=$ plasma bilirubin. Other abbreviations as in Table I. 
TABLE VI

Partial ureteral obstruction experiment*

\begin{tabular}{|c|c|c|c|c|c|c|}
\hline Time & $\mathrm{V}$ & $\mathrm{C}_{\mathrm{B}}$ & $\mathrm{C}_{\mathrm{Cr}}$ & $\mathrm{C}_{\mathrm{PAH}}$ & $\mathrm{C}_{\mathrm{B}} / \mathrm{C}_{\mathbf{C r}}$ & $\mathrm{C}_{\mathrm{B}} / \mathrm{C}_{\mathrm{PAH}}$ \\
\hline $\min$ & $m l / \min$ & $\mathrm{ml} / \mathrm{min}$ & $m l / m i n$ & $\mathrm{ml} / \mathrm{min}$ & $\%$ & $\%$ \\
\hline $\begin{array}{l}-110 \text { to }-70 \\
-70 \text { to }-65 \\
-65\end{array}$ & \multicolumn{6}{|c|}{$\begin{array}{l}\text { Prime, } 2.5 \mathrm{~g} \text { creatinine and } 100 \mathrm{mg} \mathrm{PAH} \text {, iv } \\
\text { Start sustaining infusion of } 1.4 \mathrm{mg} / \mathrm{ml} \mathrm{creatinine} \text { and } 0.32 \mathrm{mg} / \mathrm{ml} \mathrm{PAH} \\
\text { in } 6 \% \text { mannitol- } 0.6 \% \mathrm{NaCl} \text { at } 5 \mathrm{ml} / \mathrm{min}\end{array}$} \\
\hline $0-10$ & 3.1 & 0.56 & 24 & 84 & 2.4 & 0.7 \\
\hline $10-20$ & 3.3 & 0.55 & 25 & 91 & 2.2 & 0.6 \\
\hline $20-30$ & 3.7 & 0.58 & 26 & 97 & 2.3 & 0.6 \\
\hline 53 & \multicolumn{6}{|c|}{ Elevate right ureteral catheter to $+38 \mathrm{~cm}$ urine } \\
\hline $60-70$ & 3.0 & 0.48 & 22 & 108 & 2.1 & 0.4 \\
\hline $70-80$ & 3.3 & 0.50 & 23 & 113 & 2.1 & 0.4 \\
\hline 88 & \multicolumn{6}{|c|}{ Elevate right ureteral catheter to $+58 \mathrm{~cm}$ urine } \\
\hline $95-105$ & 2.8 & 0.45 & 20 & 105 & 2.3 & 0.4 \\
\hline $105-115$ & 2.8 & 0.45 & 20 & 106 & 2.2 & 0.4 \\
\hline
\end{tabular}

* Dog 4-2, $12 \mathrm{~kg}$, underwent common bile duct ligation 14 days before the experiment. Left ureter ligated 5 days before this experiment. Urine collected from right ureter. Plasma bilirubin, $3.8 \mathrm{mg}$ per $100 \mathrm{ml}$. $\mathrm{C}_{\mathrm{PAH}}=$ clearance of para-aminohippurate. Other abbreviations as in Table I.

similar to that in GFR in all experiments, regardless of whether RPF decreased or increased during the periods of partial obstruction. Figure 1 shows that the percentages of changes in $C_{B}$ were virtually the same as the percentages of changes in GFR. The regression equation for percentage of change of $C_{B}$ on percentage of change of GFR is $y=0.85 x-3.9$. The regression line for equal changes in these two parameters, that is $y=x$, is also shown. By contrast, Figure 2, which illustrates the relation between the change in $C_{B}$ and the change in RPF, indicates a tendency for

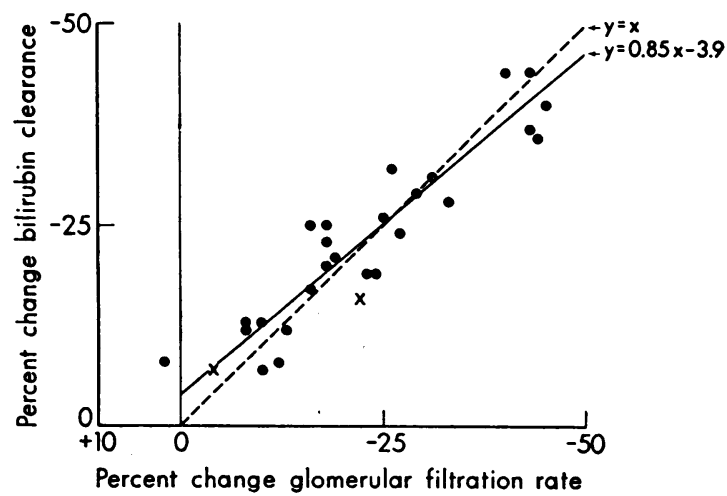

Fig. 1. Relation between change in Bilirubin CLEARANCE ( $\left.C_{B}\right)$ AND GLOMERULAR Filtration RATE (GFR) DURING PARTIAL URETERAL OBSTRUCTION. Each point is the average of two consecutive periods at the same elevated ureteral pressure. X's represent paired periods in a dog with chronic pyelonephritis. The solid line represents the regression equation for the experimental data. The dashed $45^{\circ}$ line represents equal changes in $\mathrm{C}_{B}$ and GFR. many of the points to be displaced to the left of the line $y=x$. The seven paired periods, which are indicated by open circles, represent those in which $C_{B}$, GFR, and RPF changed proportionately.

The results of three experiments are shown in Figure 3. In $\operatorname{dog} 4-2, \mathrm{C}_{\mathrm{B}}$ and $\mathrm{C}_{\mathrm{Cr}}$ decreased $12 \%$ and $8 \%$, respectively, at the first pressure level, while $\mathrm{PAH}$ clearance rose $22 \%$. At the higher pressure level $C_{B}$ and $C_{C r}$ had fallen further, while $\mathrm{C}_{\mathrm{PAB}}$ was still $16 \%$ above the control. In $\operatorname{dog} 11-2, \mathrm{C}_{\mathrm{B}}$ and $\mathrm{C}_{\mathrm{In}}$ decreased $19 \%$ and $24 \%$, respectively, while $\mathrm{C}_{\mathbf{P A H}}$ remained almost unchanged. In dog 10-1, which had chronic pyelonephritis, the increased ureteral pressure caused

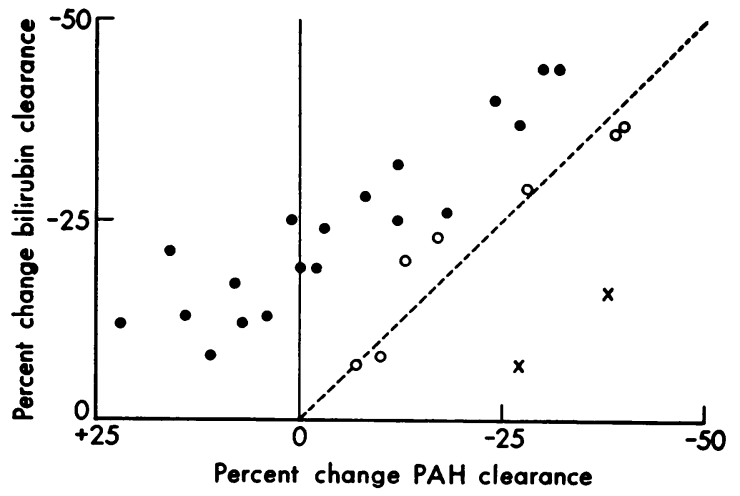

Fig. 2. Relation Between Change in Bilirubin CLEARANCE AND PARA-AMINOHIPPURATE (PAH) CLEARANCE DURING PARTIAL URETERAL OBSTRUCTION. O's represent periods in which $\mathrm{C}_{B}, \mathrm{GFR}$, and $\mathrm{C}_{\mathrm{PAB}}$ decreased proportionately. The symbols otherwise are as in Figure 1. 

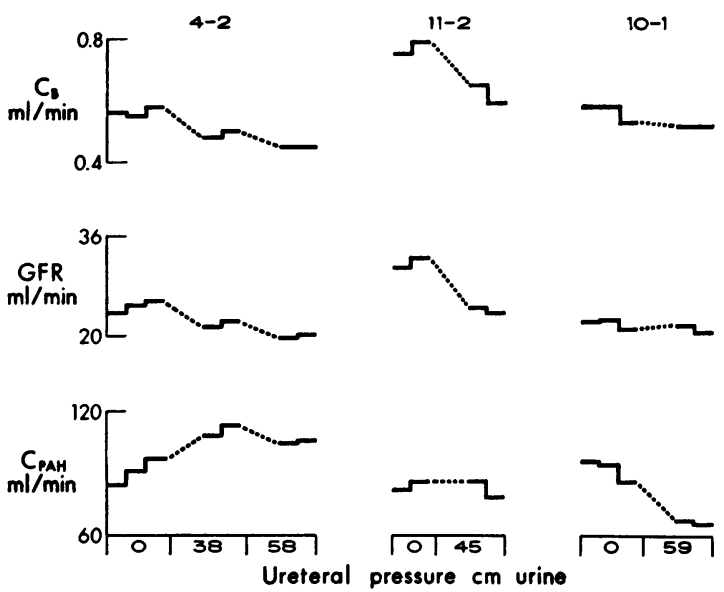

Fig. 3. Bilirubin clearance, glomerular filtraTION RATE, AND PARA-AMINOHIPPURATE CLEARANCE BEFORE AND DURING UNILATERAL PARTIAL URETERAL OBSTRUCTION. Clearance values are for dogs 4-2, 11-2, and 10-1.

little change in $\mathrm{C}_{\mathrm{B}}$ or $\mathrm{C}_{\mathrm{In}}$, while $\mathrm{C}_{\mathbf{P A H}}$ decreased $27 \%$.

Stop-flow studies. A sustaining infusion of creatinine was used in 11 of these experiments and inulin was used in four. The pattern of glucose excretion was also examined in seven of the creatinine experiments. The points in Figures 4 and 5 derive from individual experiments performed using creatinine and inulin, respectively, as indicators of water reabsorption from the tubules. The smooth curves in each figure represent the average for each group of studies. These were obtained by plotting the appropriate values from each experiment and drawing smooth curves through the points. Total nephron urine volume during occlusion was taken as that obtained from release of occlusion, to the specimen in which the glomerular marker concentration reached 50\% of its peak value. This total volume (100\%) was divided into tenths, and the clearance ratios at the mid-point of each decile were read from the curves, averaged, and plotted.

There was an abrupt rise in the bilirubin curve above the free-flow levels in specimens proximal to the one in which the glomerular marker reached $50 \%$ of its peak concentration, in eight of the 11 creatinine experiments, and in each of the four inulin experiments. That is, those specimens which contained an increasing proportion of "new filtrate" had a higher concentration of bilirubin than had been present in the free-flow urine. In the inulin experiments this "glomerular-level peak" ranged between 18 and $42 \%$ (average, $24 \%$ ) above the preobstruction free-flow $\mathrm{C}_{\mathrm{B}} / \mathrm{C}_{\text {In }}$. In that group the curve for Folin absorbance/ $\mathrm{U} / \mathrm{P}_{\mathrm{In}}$ has a similar configuration, with a peak at the same level of the nephron. The far distal peak of Folin-reactive material is similar in location to that described by Aukland in his stopflow studies of urinary protein excretion (17).

A slight trough in the bilirubin curve is evident in Figures 4 and 5. It was more prominent in the creatinine experiments, in which it was most pronounced in the proximal tubule area marked by the glucose trough. In the eight of 11 creatinine experiments in which it was found, the trough ranged from 10 to $50 \%$ (average, 26\%) below the free-flow $\mathrm{C}_{\mathbf{B}} / \mathrm{C}_{\mathbf{C r}}$. It was barely evident in the inulin experiments. There was a slight distal peak in the bilirubin curve (Figure 5 ) in four of the creatinine experiments and in one of the inulin experiments, and it was most
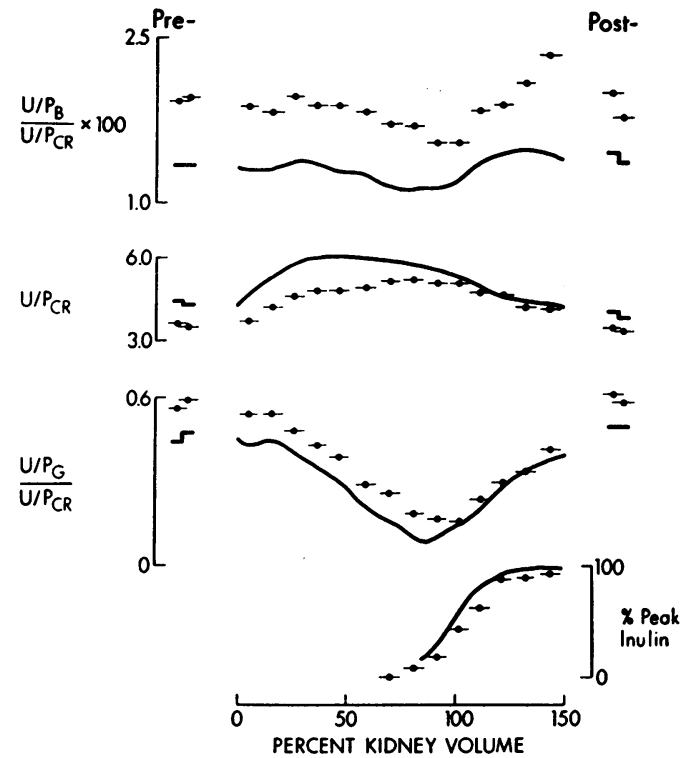

Fig. 4. Average of 11 stop-Flow STUdies̀ in JAUNDICED DOGS. Curves from above downward refer to bilirubin, creatinine, and glucose, respectively. Pre- and post- refer to the free-flow control periods. The points refer to a single experiment in $\operatorname{dog} \mathrm{N}-1,13 \mathrm{~kg}$, performed 9 days after common bile duct ligation. Plasma bilirubin, $5.3 \mathrm{mg}$ per $100 \mathrm{ml}$; priming dose, $2.8 \mathrm{~g}$ creatinine intravenously; sustaining infusion, $0.2 \%$ creatinine in $10 \%$ mannitol $-10 \%$ glucose- $0.9 \% \mathrm{NaCl}$ at $10 \mathrm{ml}$ per minute; free-flow $\mathrm{C}_{\mathrm{Cr}}, 38 \mathrm{ml}$ per minute (left kidney); rate of flow, $6 \mathrm{ml}$ per minute; $8^{\prime}$ occlusion. 

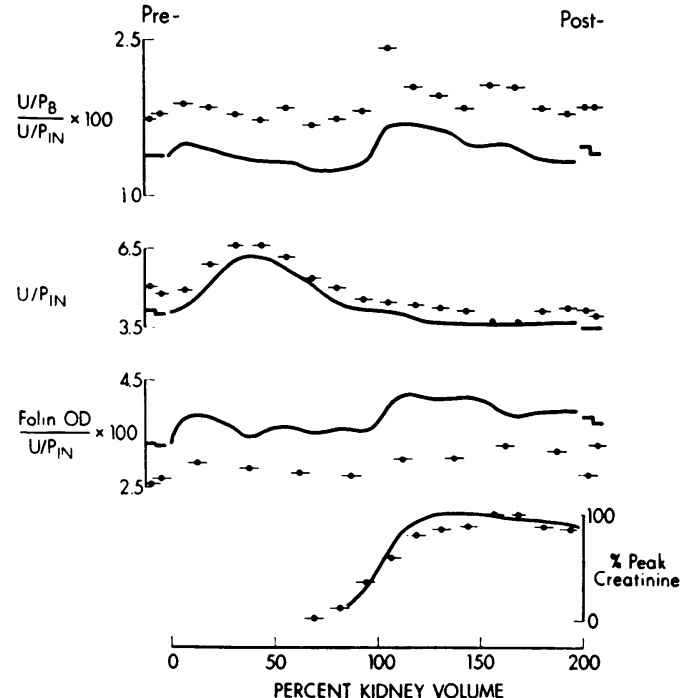

Fig. 5. Average of four stop-flow studies in JAUnDICED DOGS. Curves from above downward refer to bilirubin, inulin, and protein, respectively. Plasma protein level was constant, so that the curve for (Folin OD)/ $\left(\mathrm{U} / \mathrm{P}_{\text {In }}\right)$ effectively represents $\left(\mathrm{U} / \mathrm{P}_{\text {protein }}\right) /\left(\mathrm{U} / \mathrm{P}_{\text {In }}\right)$. The points refer to a single experiment in $\operatorname{dog} 63-3,14$ $\mathrm{kg}$, performed 10 days after common bile duct ligation. Plasma bilirubin, $3.4 \mathrm{mg}$ per $100 \mathrm{ml}$; priming dose, $3.0 \mathrm{~g}$ inulin intravenously; sustaining infusion, $0.2 \%$ inulin$10 \%$ mannitol- $0.45 \% \mathrm{NaCl}$ at $10 \mathrm{ml}$ per minute; freeflow $\mathrm{C}_{\mathrm{In}}, 35 \mathrm{ml}$ per minute (left kidney); rate of flow, $7.2 \mathrm{ml}$ per minute; $6^{\prime}$ occlusion.

prominent in that single inulin experiment. In the creatinine experiments in which it was found, it ranged from 13 to $20 \%$ (average, $16 \%$ ) above the free-flow $\mathrm{C}_{\mathrm{B}} / \mathrm{C}_{\mathrm{Cr}}$ and did not extend more than $20 \%$ of the apparent kidney volume.

\section{Discussion}

Technical considerations. A Fouchet method for determining urinary bilirubin has the disadvantage that it will include preformed biliverdin, and it could not be employed in experiments that involved the administration of salicylate. Therefore, except for two early experiments, a diazotization method was chosen. Most of the studies were done under conditions of brisk diuresis, so that the concentration of any nonbilirubin diazotizable material in the urine was minimal. The dogs received only those drugs under examination, and these were shown neither to contribute to, nor to interfere with, the Malloy-Evelyn diazo reaction for bilirubin. The close proportionality between the azobilirubin and the $435-\mathrm{m} \mu$ absorbance values corroborated the significance of the measured changes in urinary bilirubin from one clearance period to another.

The recent reports of Swanson and Hakim (18) and O'Connell, Romeo, and Mudge (19) gave evidence for the tubular secretion of creatinine. The $\mathrm{C}_{\mathrm{Cr}}$ nevertheless remains a valid estimate of the GFR in female dogs under freeflow conditions, and under these conditions creatinine was shown not to influence $\mathrm{U}_{\mathrm{B}} \mathrm{V}(20)$. The partial ureteral obstruction experiments using inulin gave results consistent with the findings in the creatinine experiments. These are therefore considered together in the later discussion. In the stop-flow experiments, however, the elevation of the $\mathrm{U} / \mathrm{P}_{\mathrm{Cr}}$ curve above free-flow levels in the proximal tubule presumably represented creatinine secretion in part. Therefore, relating $\mathrm{U} / \mathrm{P}_{\mathrm{B}}$ to $\mathrm{U} / \mathrm{P}_{\mathrm{Cr}}$ in that region yielded a trough or reabsorptive pattern that was largely spurious. That feature of the $U / \mathrm{P}_{\mathrm{Cr}}$ pattern also minimized the glomerular level peak of bilirubin.

Physiological considerations. $\mathrm{C}_{\mathrm{B}} / \mathrm{GFR}$ was not decreased by the administration of $\mathrm{PAH}$, probenecid, or salicylate. Carinamide, 2,4-dinitrophenol, and tolazoline were administered because these substances might compete with a possible bilirubin tubular secretory process, and they were also shown not to decrease $C_{B} / G F R$ (20). Several of the organic anionic agents actually caused an increase in $\mathrm{U}_{\mathbf{B}} \mathrm{V}$. Organic anionic compounds have been shown to displace unconjugated bilirubin from plasma protein (21). The increase in $\mathrm{U}_{\mathrm{B}} \mathrm{V}$ in the present studies probably resulted from an analogous displacement of conjugated bilirubin from its plasma protein carriers. The results of the present dialysis studies support this interpretation. The conditions of dialysis were not such as to assure equilibration of either the drugs or pigment between plasma and dialysis fluid. Longer dialyses were attended by variable deterioration of plasma bilirubin, and the use of larger volumes of dialysis fluid resulted in correspondingly lower absorbance measurements. There was no assurance that the absorbance values at either $435 \mathrm{~m} \mu$ or $540 \mathrm{~m} \mu$ derived solely from bilirubin. Such considerations made it unrealistic to convert these absorbancies, particu- 
larly the very low $540-\mathrm{m} \mu$ values, to total dialyzable bilirubin concentrations. The increases in plasma dialyzate absorbance following drug administration in the probenecid and salicylate experiments were nevertheless consistent with the increased urinary pigment excretion. The increase in bilirubin excretion that attended the administration of these agents might have been a consequence of inhibition of tubular reabsorption of bilirubin, but we believe this explanation to be less likely than the one already offered.

The negative studies with inhibitors and potential competitors of tubular secretion did not support the idea of proximal tubular secretion of bilirubin.

A peak in the bilirubin curve at the glomerular level was demonstrated in most of the stopflow experiments. The peak of Folin-reactive material at the same locus suggested that proteinbound bilirubin passed across the glomerular membrane during stopped flow. A similar location for a stop-flow peak in $\left(\mathrm{U} / \mathrm{P}_{\text {hemoglobin }}\right) /$ $\left(\mathrm{U} / \mathrm{P}_{\mathrm{Cr}}\right)$ has been reported (22). A peak at this level would not be expected for a freely filterable substance. A poorly filterable macromolecular substance, however, might continue to diffuse across the glomerular membrane during stopped flow because of its concentration gradient between the plasma and the glomerular urine. The finding of this glomerular peak was not interpreted as indicating the normal process of bilirubin excretion. Recent stop-flow studies of bilirubin excretion by two other groups $(23,24)$ did not report a peak at this level of the nephron. Its absence in the studies reported by Laks, Pincus, and Goldberg (23) may be attributable to their use of creatinine rather than inulin as the reference substance. A distal bilirubin peak was found in all of their studies, and in five of the nine studies reported by Iber and Chipman (24). We encountered this in four of the 11 creatinine experiments and one of the four inulin studies. This distal peak may mean tubular secretion of bilirubin. It was an inconsistent feature in these studies, however, and of limited magnitude when present.

Partial ureteral obstruction experiments were performed to dissociate GFR and RPF (25-27) in order to learn whether the $C_{B}$ changed con- cordantly with one or the other parameter. This technique is less drastic than the stop-flow method, and it has been shown not to interfere with tubular secretion of PAH (26) or phenol red (7). If bilirubin were secreted by the proximal tubules, changes in its clearance should correspond more closely with changes in RPF at excretory rates less than maximal rate of transport $\left(T_{m}\right)$. At levels well above $T_{m}$, changes in $C_{B}$ should correspond better with changes in GFR.

The finding of equivalent changes of $C_{B}$ and GFR therefore suggests that glomerular filtration does play an important role in the urinary excretion of bilirubin in dogs. It does not exclude participation of a tubular secretory process, but is suggests that if one exists, it is of modest magnitude in relation to filtration.

This technique may prove useful in examining the mode of renal excretion of other materials that are either macromolecular or bound to protein. Tubular reabsorption of a substance may preclude the finding of a clear relation to either GFR or RPF.

The nature and precise extent of the binding of bilirubin to plasma proteins must be elucidated before the renal excretory process can be fully characterized. Earlier studies in humans indicated that the circulating bilirubin was completely bound to plasma proteins $(4,5)$ and largely $(28$, $29)$ or wholly $(4,30)$ to albumin. The renal excretion of albumin is too small to account for the magnitude of the reported $C_{B}$ in either dogs or humans $(31,3)$. It might be hypothesized that a bilirubin-protein complex is filtered, bilirubin then being cleaved from protein, leaving the pigment to be excreted in the urine. This concept poses the problem that such a large amount of protein is not believed to be filtered through the glomeruli (31). It was therefore inferred that bilirubin was secreted by the renal tubules (32). This hypothesis gained credence after it was found that the urinary pigment was predominantly a glucuronide conjugate of bilirubin (1). Tubular secretion of glucuronide conjugates is recognized (33), although most of them are phenolic glucuronides, whereas conjugated bilirubin is a carboxyglucuronide (34).

The results of dialysis studies carried out in this laboratory suggest that a small fraction of 
the total plasma bilirubin in dogs and in humans (35) with obstructive jaundice is dialyzable. The circumstances of the present studies render it difficult to translate the absorbance measurements to values for total dialyzable bilirubin concentration. The values are of about the correct order of magnitude, however, to account for the observed $\mathrm{C}_{\mathrm{B}} / \mathrm{GFR}$ findings. The excretion of bilirubin by a process of glomerular filtration in chickens has also been suggested by Williamson, Robinson, and Owen on the basis of studies using the Sperber technique (36).

\section{Summary}

The renal excretion of bilirubin was studied in dogs with obstructive jaundice induced by common bile duct ligation. The administration of conventional inhibitors and competitors of tubular secretory processes did not cause any decrease in urinary bilirubin excretion. Several of the agents, having in common a considerable binding to plasma proteins themselves, caused an increase in urinary bilirubin excretion. This phenomenon was attributed to displacement of conjugated bilirubin from its carrier plasma proteins by these organic anions.

Stop-flow studies showed a peak in the bilirubin curve at the glomerular level, which was interpreted as arising from glomerular filtration of protein-bound bilirubin during ureteral occlusion. A small distal peak may represent a secretory locus of modest capacity, but has not been demonstrated consistently.

When the induction of partial ureteral obstruction caused a greater decrease of glomerular filtration rate than renal plasma flow, bilirubin clearance was found to parallel the former closely and to diverge from the latter. These studies suggest predominance of glomerular filtration over tubular secretion in the renal excretion of bilirubin.

\section{Acknowledgments}

The authors are grateful to Dr. Alfred Gilman for his advice and criticism, to Miss Alma Annexy for her capable technical assistance, and to Mr. Albert Hanok for the use of equipment in his laboratory.

The dialysis experiments were carried out in collaboration with Dr. John I. Sandson of the Department of Medicine, Albert Einstein College of Medicine.

\section{References}

1. Schmid, R. Direct-reacting bilirubin, bilirubin glucuronide, in serum, bile and urine. Science 1956, 124, 76.

2. Klatskin, G. Bile pigment metabolism. Ann. Rev. Med. 1961, 12, 231.

3. Gray, C. H. Bile pigments in health and disease. Springfield, Ill., Charles C Thomas, 1961, p. 53.

4. Snapper, I., and W. M. Bendien. On the physicochemical condition of the bilirubin in the blood serum and urine. Acta med. scand. 1938, 98, 77.

5. Barac, G. Interactions of bilirubin with plasma proteins, and the state of bilirubin in normal human plasma. Arch. int. Physiol. 1953, 61, 129.

6. Weber, A. Ph., and L. Schalm. Quantitative separation and determination of bilirubin and conjugated bilirubin in human serum. Clin. chim. Acta 1962, 7, 805.

7. Malvin, R. L., W. S. Wilde, and L. P. Sullivan. Localization of nephron transport by stop flow analysis. Amer. J. Physiol. 1958, 194, 135.

8. Pitts, R. F., R. S. Gurd, R. H. Kessler, and K. Hierholzer. Localization of acidification of urine, potassium and ammonia secretion and phosphate reabsorption in the nephron of the dog. Amer. J. Physiol. 1958, 194, 125.

9. Thoma, G. E., and D. M. Kitzberger. A spectrophotometric method for determination of urinary bilirubin. J. Lab. clin. Med. 1948, 33, 1189.

10. Malloy, H. T., and K. A. Evelyn. The determination of bilirubin with the photoelectric colorimeter. J. biol. Chem. 1937, 119, 481.

11. Bonsnes, R. W., and H. H. Taussky. On the colorimetric determination of creatinine by the Jaffe reaction. J. biol. Chem. 1945, 158, 581.

12. Higashi, A., and L. Peters. A rapid colorimetric method for the determination of inulin in plasma and urine. J. Lab. clin. Med. 1950, 35, 475.

13. Smith, H. W., N. Finkelstein, L. Aliminosa, B. Crawford, and M. Graber. The renal clearances of substituted hippuric acid derivatives and other aromatic acids in dog and man. J. clin. Invest. 1945, 24, 388.

14. Nelson, N. A photometric adaptation of the Somogyi method for the determination of glucose. J. bio!. Chem. 1944, 153, 375.

15. Lowry, O. H., N. J. Rosebrough, A. L. Farr, and R. J. Randall. Protein measurement with the Folin phenol reagent. J. biol. Chem. 1951, 193, 265.

16. Toribara, T. Y., A. R. Terepka, and P. A. Dewey. The ultrafiltrable calcium of human serum. I. Ultrafiltration methods and normal values. J. clin. Invest. 1957, 36, 738.

17. Aukland, K. Stop flow analysis of renal protein excretion in the dog. Scand. J. clin. Lab. Invest. 1960, 12, 300.

18. Swanson, R. E., and A. A. Hakim. Stop-flow analysis of creatinine excretion in the dog. Amer. J. Physiol. 1962, 203, 980. 
19. O’Connell, J. M. B., J. A. Romeo, and G. H. Mudge. Renal tubular secretion of creatinine in the dog. Amer. J. Physiol. 1962, 203, 985.

20. Fulop, M., and P. Brazeau. Unpublished observations.

21. Odell, G. B. Studies in kernicterus. I. The protein binding of bilirubin. J. clin. Invest. 1959, 38, 823.

22. Malmendier, C. L., J. P. DeKoster, F. V. Veiken, H. Brauman, M. deMyttenaere, and P. P. Lambert. Stop-flow analysis applied to the excretion of hemoglobin. Amer. J. Physiol. 1960, 199, 292.

23. Laks, M. M., I. J. Pincus, and D. Goldberg. Renal excretion of bilirubin in the common duct ligated dog. Gastroenterology 1963, 44, 469.

24. Iber, F. L., and B. R. Chipman. Excretion of bilirubin in dogs studied by "stop flow" analysis (abstract). Gastroenterology 1963, 44, 479.

25. Share, L. Effect of increased ureteral pressure on renal function. Amer. J. Physiol. 1952, 168, 97.

26. Selkurt, E. E., M. Brandfonbrener, and H. M. Geller. Effects of ureteral pressure increase on renal hemodynamics and the handling of electrolytes and water. Amer. J. Physiol. 1952, 170, 61.

27. Abbrecht, P. H., and R. L. Malvin. Effects of GFR and renal plasma flow on urine osmolarity. Amer. J. Physiol. 1961, 201, 754.
28. Gray, C. H., and R. A. Kekwick. Bilirubin-serum protein complexes and the van den Berg reaction. Nature (Lond.) 1948, 161, 274.

29. Klatskin, G., and L. Bungards. Bilirubin-protein linkages in serum and their relationship to the van den Berg reaction. J. clin. Invest. 1956, 35, 537.

30. Coolidge, T. B. Chemistry of the van den Berg reaction. J. biol. Chem. 1940, 132, 119.

31. Smith, H. W. The Kidney. Structure and Function in Health and Disease. New York, Oxford University Press, 1951, p. 219.

32. With, T. K. Bilirubin in urine and other secretions apart from the bile and in the cerebrospinal fluid and eye liquors. Acta physiol. scand. 1945, 10, 355.

33. Sperber, I. Secretion of organic anions in the formation of urine and bile. Pharmacol. Rev. 1959, 11, 109.

34. Schachter, D. Nature of the glucuronide in directreacting bilirubin. Science 1957, 126, 507.

35. Fulop, M., J. I. Sandson, and P. Brazeau. Manuscript in preparation.

36. Williamson, I., R. R. Robinson, and E. E. Owen. Mechanism of bilirubin excretion by avian kidney. Amer. J. Physiol. 1963, 205, 267. 